N. Vergara, E. Barraza. Desde el borde de unas aguas fronterizas: para una lectura de Desde el fogón de una casa de putas williche de Graciela Huinao

\title{
DESDE EL BORDE DE UNAS AGUAS FRONTERIZAS: PARA UNA LECTURA DE DESDE EL FOGÓN DE UNA CASA DE PUTAS WILLICHE DE GRACIELA HUINAO ${ }^{1}$
}

\section{FROM THE EDGE OF BORDER WATERS: FOR A READING OF DESDE EL FOGÓN DE UNA CASA DE PUTAS WILLICHE BY GRACIELA HUINAO}

\author{
Nelson Vergara \\ Universidad de Los Lagos \\ nvergara@ulagos.cl \\ Eduardo Barraza \\ Universidad de Los Lagos \\ ebarraza@ulagos.cl
}

\begin{abstract}
Resumen:
Desde el fogón de una casa de putas williche ${ }^{2}(2010)$ es un relato que propone una réplica a las categorías multiculturales e historiográficas (Ramay, 2013) con las cuales se han abordado las relaciones de las culturas en contacto en Chile. El locus de enunciación textual corresponde a una voz histórica y étnicamente

identificada que se pronuncia desde una de las orillas del río Rahue en instantes cuando al lado oriental del río emerge la población urbana de Osorno, suceso que se pronuncia mediante una voz propia no cruzada estrictamente por formaciones academicistas ni hibridaciones transculturales. Desde este margen, el narrador textual apela constantemente a una identidad primera ("No soy chilena pues naci williche", dice Graciela Huinao) que traduce una mirada y una condición de voz autorial en resistencia (Guerra, 2011) emitida desde una instancia fronteriza articulada por el río (Andrade 2014). Por lo mismo -según analizaremos en este artículose trata de un texto que ya desde el título, y desde una periferia cultural, polemiza con las diversas nociones academicistas relativas a la territorialidad y a la transculturalidad (Ortí, 1978; Rama, 1982) y pone al descubierto los trazos fronterizos de interculturalidad en su condición híbrida, precaria e inarmónica.
\end{abstract}

Palabras clave: narrativa mapuche, transculturalidad, etnicidad, identidades, fronteras.

\section{Abstract:}

Desde el fogón de una casa de putas williche (2010) is a story that proposes a reply to the multicultural and historiographic categories (Ramay, 2013) with which have dealt with the relations of cultures in contact in Chile. The locus of textual enunciation corresponds to a historically and ethnically identified voice that is pronounced from one of the banks of the river Rahue in moments when to the eastern side of the river emerges the urban population of Osorno, event that is pronounced by means of a own voice not crossed strictly by academic formations or transcultural hybridizations. From this margin, the textual narrator constantly appeals to a first identity ("I am not Chilean because I was born williche", Graciela Huinao says) that translates a look and a condition of authorial voice in resistance (Guerra, 2011) from a frontier condition articulated by the river (Andrade, 2014). For the same reason - as we will analyze in this article - it is a text that already from the title, and from a cultural periphery, polemizes with the diverse academic notions regarding

\footnotetext{
${ }^{1}$ Artículo derivado del Proyecto DI 10/2016 que patrocina la Universidad de Los Lagos.

2 Conforme al texto original, decidimos conservar grafías como "williche", "Rawe", "lafkenche", "winka", "Chaurakawin" reservando para nuestro artículo las normas de escritura vigentes al respecto.
} 
Nueva Revista del Pacífico 2017, No 66, (196-208). ISSN 0716-6346, ISSN (e) 0719-5176

territoriality and transculturality (Ortiz, 1978; Rama, 1982) and exposes the frontier traces of interculturality in its hybrid, precarious and inharmonious condition.

Key words: Mapuche narrative, transculturality, ethnicity, identities, borders.

Recibido: 30/5/2017

Aceptado: $30 / 6 / 2017$

0. El objetivo de este trabajo no es un análisis de valores estéticos que pueden hallarse presentes o latentes en el texto. Tampoco es una reflexión sobre un posible valor testimonial del relato, y, eventualmente, de sus narradores o personajes. Más bien, es un ejercicio que aspira cotejar intuiciones literarias con conceptos teóricos catalogados como noeurocéntricos, sean de orígenes latinos o europeos ${ }^{3}$. En este plano, nos situamos en imágenes, representaciones e imaginarios sugeridos por la expresión "desde el borde de unas aguas fronterizas", metáfora que revela por un lado, la condición del río Rahue como una realidad que deviene, que transcurre, y que se proyecta en el barrio del mismo nombre, así como también, por otro lado, que identifica las vidas confrontadas que nacen y viven en ambas riberas: la huinca y la huilliche.

En el relato Desde el fogón de una casa de putas williche, sin embargo, la mirada, no es neutral. Ella se sitúa y se manifiesta como originariamente huilliche, por lo mismo, se trata de una "mirada" que proviene de una memoria ancestral profunda y a ella acercamos los conceptos interpretativos.

Consideremos, básicamente, que el locus de enunciación textual se sitúa a orillas del río Rahue en instantes cuando -luego de la llamada Pacificación de la Araucanía- al lado oriental del río emerge la población urbana y la cultura de huinca y de colonos en Osorno, suceso que se pronuncia mediante una voz propia, no cruzada estrictamente por formaciones academicistas ni hibridaciones transculturales. Desde la orilla poniente, el narrador textual enuncia el "manifiesto" de un sujeto huilliche que apela constantemente a una identidad primera, lo cual traduce una mirada y una condición de voz autorial en resistencia que se enuncia en defensa de la cultura propia (Guerra, 2011). Se trata de una identidad histórica y

\footnotetext{
${ }^{3}$ De preferencia, E. Lander (2005), B. de Sousa Santos (2013), Cornelius Castoriadis (2007) y lo que, en general, se conoce hoy como pensamiento crítico latinoamericano. Entre otros, Santiago Castro-Gómez (2005), Nelson Maldonado-Torres (2008), Walter Mignolo (2005), Enrique Dussel (2005), Arturo Escobar (2016), Anibal Quijano (2005) etc, quienes desarrollan la crítica más reciente y radical a los postulados básicos de la Modernidad/Colonialidad.
} 
N. Vergara, E. Barraza. Desde el borde de unas aguas fronterizas: para una lectura de Desde el fogón de una casa de putas williche de Graciela Huinao

étnicamente situada, no mimetizada ni en la voz ni en la mirada "huinca" de modo tal que así puede hablar con propiedad a esos otros sujetos de una presumida ciudad letrada (Rama 1982).

Conforme a lo anteriormente expuesto, el itinerario que seguirá este artículo será el siguiente: a) aproximación a la metáfora básica que se revela en el título del trabajo; b) mirada reveladora del proceso de usurpación progresiva de la condición identitaria huilliche en el relato de tres personajes claves; c) relación del relato con conceptos teóricos del pensamiento crítico. Esta relación, sin embargo, no tiene como objetivo subsumir lo literario en lo teórico, sino que más bien mostrar su coherencia. Empezamos, entonces, con una reflexión en torno a los términos que componen nuestra expresión "desde el borde de unas aguas fronterizas".

1. En primer lugar, el punto de partida de la interpretación, el lugar donde se origina el relato lo entendemos como un principio, como el "desde donde", fáctica y conceptualmente, algo empieza a ser, decidiéndose por un modo determinado de ser, modo que nos relata también de qué manera se accede a ese ser, entendido fundamentalmente como un sentido de ser. En todos estos casos, se trata del ser huilliche, lo que incluye también el modo en que, aún en la mayor adversidad, se mantiene ese ser.

A nuestro juicio, este principio se materializa y representa de dos modos originarios que se dan al mismo tiempo: como borde de aguas y como fronteras. No son, por tanto, dos modalidades autónomas que pueden entrar en relaciones de sucesividad. Por el contrario, sostenemos que no se preceden o suceden, sino que se dan conjuntamente en un mismo acto de enunciación que las refiere en mutuas referencias. Entonces, las aguas son fronterizas, al mismo tiempo que esas fronteras son dinámicas, puro movimiento. Esta conjunción tiene, para nosotros, profundas consecuencias ya que revela el encuentro/desencuentro de racionalidades antagónicas que serán determinantes en las relaciones asimétricas de ambos mundos, y, por lo mismo, reveladora de su condición de colonialidad ${ }^{4}$.

Digamos, entonces, que, en nuestro caso, la construcción de la frontera no es un hecho natural sino histórico-social y no alude a realidades construidas por la solidez de un

\footnotetext{
${ }^{4}$ Colonialidad, entendida por Edgardo Lander, en términos de establecer que con el inicio del colonialismo en América, comienza no solo la organización colonial del mundo, sino -simultáneamente- la constitución colonial de los saberes, de los lenguajes, de la memoria y del imaginario" (2005: 7).
} 
fuerte, un muro, un barrio, un puente, una montaña, una pradera, o un desierto. Sino que, por el contrario, estas fronteras se construyen como fluencias $\mathrm{y}$, por eso, son realidades inestables $\mathrm{y}$, por inestables, inciertas e inseguras, siempre amenazadoras de desbordes, rupturas o de desvío de cauces, haciendo inalcanzable la estabilidad de una total permanencia $^{5}$.

Como frontera, el río fluye, trayendo y llevando la vida, poniendo condiciones a la existencia, condiciones que por su naturaleza líquida son siempre azarosas, arbitrarias, y sujetas a una voluntad que trasciende todo deseo y todo sueño, para entronizarse en la naturaleza, la historia y la divinidad. De este modo, las aguas se tornan realidades mágicas o míticas y en estas situaciones exigen ceremonias y rituales, tanto para manifestarse como también, eventualmente, para ocultarse.

En el relato, las aguas fronterizas son reforzadas con la imagen de la niebla que se posa habitualmente sobre el río, y que como tal, trae y lleva incertidumbres, descubre o encubre posibles acechanzas que deben ser conjuradas constantemente. De aquí el valor cuasi religioso que asume la palabra narradora cuando acoge el desafío de situar un origen biográfico al barrio que va naciendo en el borde de esas aguas:

lo parieron allegado a territorio williche, sin registro en la historia [...] Estoicamente levantó su primera casa, luego ésta parió a otra..._Así nació y fue creciendo..., en las faldas de un cerro, que en su justa medida lo corta un río (13)

Pero, esta situación mágica ubica, también, a quienes van a contribuir con la narración de la historia, haciéndose parte de ella. Así la narradora se dirige a su propio principio identitario, como un lugar en que no se puede discernir totalmente lo efectivo de lo mítico:

de a poco comencé a empinarme en medio de las letras, sujetada de mis poemas ingenuos, siendo mis primeros pasos trancos amparados por relatos de

\footnotetext{
${ }^{5}$ En general, como analiza Tatiana Calderón, el concepto de frontera es "hermético" y "permeable", a la vez. No solo remite a un límite físico. También connota "margen, confin, línea, franja, borde", división, separación, barrera entre un territorio concebido como propio y otra territorialidad diferente, cuando no enajenada o separada de la propia, lo cual implica "problemáticas históricas, sociales y políticas" tanto como otras relativas a un nivel imaginario, discursivo y simbólico que refiere a la configuración y "reconfiguración de las identidades nacionales y culturales" (2015: 21).
} 
N. Vergara, E. Barraza. Desde el borde de unas aguas fronterizas: para una lectura de Desde el fogón de una casa de putas williche de Graciela Huinao

brujos y duendes que volaban entre mis páginas en el país de mi infancia: el sur (10).

Y, quizás, por esto también, por dar cuenta de un origen inesperado (marginado de su historia) y sin elección -por su pertenencia a lo mágico de sus mundos- los primeros pobladores, antes recolectores y pescadores, no perdieron jamás la esperanza de un retorno al "país de la infancia", a esos espacios propios, familiares, acogedores. Digamos mejor, que nunca renunciaron a la posibilidad de un reencuentro con sus montes y costas y que, por esto, se les vio "bajar con una carga de necesidades", y es muy probable que entonces, según dice el relato

al río lo vier[a]n como un pequeño mar, y apegar[a]n su rogativa diaria a orillas de las aguas, para que la oración, como antigua canoa llegue por el río hasta el mar, a tocar la puerta del Abuelo Wentriao, para que la vida no les sea tan porfiada al caminar (14)

De esta manera, a partir de un nacimiento sin alternativa, el barrio crece asentándose en la ribera huilliche del río, y así, las:

que un día fueron huellas dejadas por los williche, con su paso hacia la costa, a la celebración de su Ngillatún, ahora son calles que el tiempo ha ido arando y que en la cara del mapa se ven como arrugas que el tiempo surcó. Aunque viejo, el barrio es saludable y con tranco seguro avanza [...] de vez en cuando mira atrás para no perder de vista la memoria y el río humedece los recuerdos, incluso los que ya no están. (15)

2. Pero el borde de unas aguas refiere, de distintos modos, su condición de instancia fronteriza, esto es, de espacios en que entran en contacto distinciones y diferencias, límites materiales y simbólicos que remiten a identidades que han entrado en conflicto. La frontera no es entonces un mero hito físico-geográfico, sino más bien un lugar de encuentro/desencuentro de mundos, así como también, por el valor atribuido a la palabra, un lugar de enunciación de esos desencuentros.

Desde este margen de locución, delimitado y articulado por el río, el narrador textual apela constantemente a su identidad primera de huilliche (Andrade 2014). Mediante esta estrategia, esta voz narrativa polemiza con los discursos de distanciamiento y ajenidad que la voz chilena ha proferido respecto a una presunta "ciudad iletrada" huilliche, cuya frontera 
demarca tanto el río Rahue como el fuerte construido por los conquistadores en la orilla huinca en el siglo XVIII ${ }^{6}$.

Por lo anterior, reiteramos entonces que no hay una frontera única y unívoca, sino múltiples fronteras claramente diferenciadas. Entre ellas, la más evidente, la que parece saltar a la vista de una primera impresión y que separa lo que está de este lado del río, es decir, el borderrío del Rahue, y lo que está del otro lado del río, esto es, la ciudad de Osorno, ambas riberas abiertas a sus propios mundos y cerradas, clausuradas, a los mundos ajenos.

Pero hay otra frontera tan material como la anterior: la que separa la vida urbana, ciudadana, de la experiencia rural, campesina; frontera que cada vez se hace más móvil, invasora y violenta al adentrarse, desplazar y ocupar los mundos huilliche, acorralando a sus habitantes, separándolos de sus historias y obligándolos a incorporarse a la periferia de las ciudades, lugares en que las fronteras, antes rurales, se tornarán límites de exclusión ciudadana. Con el tiempo, estos límites se desintegrarán en simples periferias, en márgenes degradados, en espacios que la exclusión hará invisibles, inexistentes, irreales ${ }^{7}$.

Una tercera frontera, más violenta e insolidaria que las anteriores es, sin embargo, la frontera simbólica, cultural, que irá negando al huilliche el derecho a ser lo que ha venido siendo desde el origen, para intentar transformarlo en lo que el Estado quiere que sea. Entonces, este desplazamiento obligado será identificado como in-exilio. Como "exilio en su propia tierra" (16) se dice en el texto. Así, el obligado desplazamiento del campo a la ciudad y la sensación creciente de no poder revertir el despojo, sólo deja lugar a un retorno momentáneo, ocasional, al momento de un eventual reencuentro familiar obligado por las circunstancias. Pero, aún en estas situaciones de eventuales y esporádicos reencuentros, "hasta la naturaleza manifestaba su alegría, con los graznidos de los treiles que eran los

\footnotetext{
${ }^{6}$ Por lo mismo, se trata de un texto que ya desde el título, y desde una periferia cultural, polemiza con las diversas nociones teóricas relativas a la territorialidad y a la trans-culturalidad (Ortiz, 1978; Rama 1982, Dussel, 2005; Fornet-Betancourt) y pone al descubierto los trazos fronterizos de interculturalidad en su condición híbrida precaria e inarmónica: lo urbano es Osorno que desplaza al originario Chauracahuín, vale decir, lo civilizado, (la "casa" de filiación huinca) vs lo rural, in-civilizado, (la "ruca" y el "fogón" huilliche"). Por lo demás, el río es una barrera física que exige ser superada por los sucesivos puentes que se han construido sobre su cauce desde comienzos del siglo XIX lo cual, hipotéticamente da paso al tránsito, al intercambio cultural entre las dos orillas. Sin embargo, contrariamente a las perspectivas de la dinámica intercultural, a nuestro juicio, desde la orilla huilliche en Desde el fogón.... se despliega y se declara una frontera de resistencia cultural que desactiva los discursos que la sociedad huinca ha proferido sobre su contraparte huilliche y actualiza la lengua propia como uno de los signos de identidad originarios.

${ }^{7}$ B. de Souza Santos, 2013, capítulo 2, "Más allá del pensamiento abismal: de las líneas globales a una ecología de saberes".
} 
N. Vergara, E. Barraza. Desde el borde de unas aguas fronterizas: para una lectura de Desde el fogón de una casa de putas williche de Graciela Huinao

primeros en dar la bienvenida al "visitante"” (18). Alegría genuina, y sin embargo, subsidiaria e intermitente, momentánea y sin continuidad real, relaciones fronterizas, en verdad, pero sin alma propia y sin anclajes ${ }^{8}$.

3. Pero, ¿por qué las fronteras instalan, no sin violencia, un nuevo sentido territorial y, por retroefecto, una no menos violenta comprensión de la pérdida y validación de ese sentido para unos y para otros?

De la tierra al territorio se podría nombrar el proceso de usurpación y exilio, relatado en Desde el fogón..., proceso que cubre todo el espacio vivido, desde el mar a la cordillera y desde la montaña al mar, lo que metafóricamente parece anunciar acontecimientos contradictorios: atardeceres que se muestran como inminentes y, sin embargo, al mismo tiempo, deseos fervorosos de amaneceres brillantes otra vez.

En Desde el fogón..., los protagonistas más emblemáticos revelan este curso de las cosas que, en destinos paralelos, ilustran el viaje en que se encontrarán entramados en un solo sitio posible: en el centro de un drama que entonces recién comienza a representarse en las riberas movedizas del río. Allí, el naciente barrio borderrío acogerá a estos expulsados de la tierra e intentará recrear aunque deformados, los mundos de ayer, perdidos y reencontrados constantemente en el fondo de las memorias. Destinos diferentes que, sin embargo, se entrelazan solidariamente frente a un mundo que quiere ser único al instalar la regulación y el orden venido de lejos ${ }^{9}$.

Pichún, Kintún y el "Marcao" son emblemáticos seres huilliche-lafquenche que asumen la responsabilidad de vivir ese primer exilio que los saca de sus tierras y los

\footnotetext{
8 "Relaciones fronterizas" es un concepto acuñado por la historiografía de la conquista (Villalobos, 1982, 1995) para delimitar la soberanía sobre un territorio en proceso de pacificación -o en paz- conquistado por los españoles frente al territorio por conquistar -en pie de guerra y por ello "bárbaro"- en posesión de los mapuches. Su prototipo histórico-cultural remite a las "aguas fronterizas del río Bío-Bío" cuyo margen norte es el de la dominación siendo el sur el de la resistencia mapuche. Se trata de un territorio de mediación transicional cuya dinámica es la instauración de un presumible circuito de paz (no resistencia mapuche) y de interacción entre dos bandos. Desde una perspectiva cultural, las relaciones fronterizas han sido estimadas como espacios "movedizos y porosos, en los cuales se produce un incesante desplazamiento de sujetos a un lado y al otro de la frontera", los que provocan "contactos e intercambios culturales, la formación de zonas intermedias de lenguaje y procesos de traducción"... pero también "tensiones colonizadoras y acciones decolonizadoras de los espacios naturales y culturales, así como en la redefinición de las identidades" (Mora, Edith, 20).

${ }^{9}$ En el marco de los estudios culturales, el análisis del término frontera refiere a "un acto de visibilización de inequidades y resistencias y negaciones ocultas o explícitas frente al poder. Acentúa, en particular, actos de demarcación de límites, asimetrías”. (Belausteguigoitía 2009:107).
} 
introduce en las aguas movedizas de las nuevas fronteras. Ellos se enfrentan a los límites que entonces empiezan a insinuarse desde la violencia y la pérdida de lo más preciado e íntimo: la tierra y la lengua y, finalmente el nombre.

El peñi Pichún nació en la costa y la brisa del mar curtió su piel lafkenche en invierno y en verano, y es de suponer que la huella de sal de sus primeros pasos, sobre el dulce musgo de una oca aromatizada por la murta, tal vez se ha petrificado a orillas del imponente mar williche (46)

Pero Pichún es emblemático porque en él se conjugan fuerzas antagónicas que salen al paso de la resignación. En este contexto leemos que, si bien una "muda adolescencia lo encontró de inquilino del campo del que una vez fuera dueño"... "la usurpación lo dejó fuera de la escuela y que para trazar la tierra sólo necesitó empuñar un azadón”, frente a todos “estos atropellos desarrolló una habilidad impresionante al sumar y restar”, y lo más significativo es que "era poseedor de una claridad brillante al relatar los acontecimientos históricos de su pueblo, los cuales nítidamente fueron traspasados a su descendencia" $(23)^{10}$.

Kintún, al contrario de Pichún, fue marcado por acontecimientos en que se enfrentan la nación huilliche con el Estado chileno en la construcción del futuro. Heredero de guerreros, su familia es también arrinconada en la peor tierra y desde allí debe asistir al proceso de pérdida de los mundos que simbolizan sus territorios. El encarna el caso de quienes deben asistir al trato de la urbe civilizatoria que va a despojarlos de sus mundos: el bautizo, la educación, el trabajo insolidario de miembros de su propio linaje, quienes, transformados a la nueva moral, hacen compatible la indolencia con la nueva ambición.

Del peñi Kintún se cuenta que lo parieron en la cordillera y, al pie de los Andes, su corazón de niño... aún ensaya una prueba de amor que nunca aprobó y que en las calurosas noches de verano, un relámpago que algún volcán milenario hace resplandecer... alumbrando su antigua sonrisa sobre las aguas de los grandes lagos del sur (46

\footnotetext{
${ }^{10}$ C Castoriadis (2007), principalmente capítulo VII, sobre las "Significaciones imaginarias sociales", detalla las dimensiones del contar como esenciales a toda sociedad, acción que se expresa indistintamente tanto en las dimensiones aritméticas como en las narrativas. Así numerar y mitificar son consustanciales a los sujetos en toda sociedad.
} 
N. Vergara, E. Barraza. Desde el borde de unas aguas fronterizas: para una lectura de Desde el fogón de una casa de putas williche de Graciela Huinao

Así, al peñi Kintún su cosmovisión de niño le enseñó que:

uno de los métodos más efectivos de dominación era la imposición de una lengua ajena, que paulatinamente se fue posicionando y cambiando los valores ancestrales a la mayoría de su gente. Incluso trayendo a su pueblo para siempre uno de los daños culturales casi imposible de recuperar: su lengua vernácula. (41)

Entonces, apunta la narración, esta fusión de destinos se lleva a cabo en la "casa de putas" lo que se destaca al decir que:

Dos almas de macho adolescentes, huérfanos de selva y mar, se acurrucaron al nuevo barrio que empezaba a levantar sus casas a orillas del Rawe, cuando aún no tenía capacha, iglesia ni escuela, pero al final de su calle principal, se encontraba igual que una gallina clueca echada, la memorable casa de remolienda "La trompa de pato". No fue casualidad que estos dos naturales se conocieran en una casa de putas, por el contrario, las trabajadoras llevaban el imán en la sangre y ese lazo, Pichún y Kintún nunca pudieron cortar. (46)

Pero esta larga historia del borderrío huilliche, contada de muchas maneras, no podría terminarse sin una referencia a un tercer personaje que, a nuestro juicio, manifiesta la clausura cuasi definitiva de estos mundos: la reveladora historia del "Marcao", extraño personaje que ha perdido todo, hasta el nombre, y con ello su condición más íntima. El capítulo titulado "Robaron mi ser" (139), anuncia y denuncia el relato de su historia. Por medio de ella, sabemos que ya no es solamente la tierra, sino el territorio que refiere y remite, también, la pérdida del ser, la identidad.

Llevado por las fuerzas del Estado que lo arrastran al "servicio militar", el "Marcao" es conminado a despojarse de su identidad, al extremo que deberá renunciar a su nombre originario. Porque claro es que para enrolarlo en las fuerzas militares deben preguntarle cómo se llama. A tal pregunta responde con el nombre que se le ha dado en su lengua: "Pichialka... Alka" (148). Frente a tal respuesta, el uniformado a cargo del reclutamiento repetirá desesperadamente: "No ves que yo no sé escribir esa gueá de nombre". 
Entonces, un subalterno champurria -mestizo- le indica a su jefe que proceda del mismo modo que hizo con los otros reclutas. Y así, tomando una vez más un viejo almanaque que tiene a mano, su mirada se posa en un anuncio comercial de una "Pulpería Alarcón". Entonces dictamina de una vez para siempre: "Desde hoy este indio gueón se llamará: Juan Alarcón” (148)

Pero, a Pichialka no solamente le dieron un nombre en otra lengua a cambio del suyo propio. Además, siguiendo lo que será habitual con el tiempo, el huilliche champurria ya "incorporado" a la nación chilena, será quien -en mapudungun- le haga notar a este Juan Alarcón, recién bautizado como soldado "chileno":

la importancia que tendría en su vida, el día que le entregaron a su ser, un nuevo espíritu y que hasta el día de su muerte lo iba a agradecer, por tratarse de un espíritu más digno.... y que nunca más sería williche, porque desde ese día, su espíritu antiguo había muerto y un nuevo espíritu chileno crecería dentro de su ser. (148-149)

En síntesis, Desde el fogón... pone de manifiesto que en situaciones de fronteras fruto de la dominación, como las heredadas de la conquista española, "el pasaje entre espacios fronterizos" (Calderón, 2015: 30) obedece a un rito irreversible en que triunfa el ceremonial del dominador. La frontera natural del Rahue -que obligaba a atravesarlo a nado- es anulada por un kui-kui (28), un puente que atraviesa el río, puente con el cual "las nuevas autoridades para facilitar el despojo habían apuñalado de lado a lado su respetado río" (28). Por esto, la orilla huinca del Rahue se vislumbra como el territorio de la opresión, que impone dejar de ser huilliche: esto es, que somete a uno a la cultura, las leyes civiles, judiciales y militares del otro; a su religión, su lengua, su escritura, su educación.

Por lo mismo, concluimos que -situado temporalmente hacia mediados del siglo XIXel texto de Graciela Huinao advierte que la frontera natural entre el territorio de Rahue y el Chaurahuin (marcada por el río de Las Canoas) no es simplemente "una zona de contacto" sino "de dominación" irremediable por lo cual el huilliche se resiste al tránsito o al rito "de pasaje" entre su cultura y la llamada "civilización del huinca" (Calderón 30). Tal resistencia tiene su raíz en que -ante el huilliche- la civilización huinca se presenta en términos de expropiación de la tierra, negación de su religión, pérdida de su lengua, todo lo cual los 
N. Vergara, E. Barraza. Desde el borde de unas aguas fronterizas: para una lectura de Desde el fogón de una casa de putas williche de Graciela Huinao

transforma en "exiliados en su propia tierra" (16-19), en sujetos no conminados a padecer un "exilio exterior" -una nomadía- en un territorio ajeno sino un in-silio, a partir de la reversión de un estatus identitario ("inquilino de un campo del que un día fuera dueño") como ocurre a Pichún (23). Se configura, así, una existencia en desequilibrio, que se expresa en el modo de un estar entre dos lenguas, dos culturas disímiles; dos tiempos (el presente del invasor y el del admapu); entre dos espacios: el propio y el ajeno (el lado de acá del río Rahue; mi lado y el lado de allá del río, el de aquellos que ahora ocupan Chauracahuin, el lado que era mío). En suma, se trata de identidades irresueltas: de la huilliches y de mestizos champurreando entre dos lenguas, entre dos historias; entre mi ruca ancestral y la casa europea de ellos (huincas y colonos).

Por esta vía se puede concluir que en este texto, Graciela Huinao pone de manifiesto la condición intersticial de toda frontera, en tanto, táctica ya no solo de reprimir sino de subordinar, "invisibilizar toda aquella otredad que pueda colindar, oponerse u ocultarse". En términos de M. Belausteguigoitía la "función epistemológica y crítica de la frontera radica en el hecho de transparentar" los "efectos del ejercicio del poder y la resistencia", propiciando "retornos estratégicos de lo local" o de lo propio, "con el fin de revisar paradigmas estrechos de identidad" (2009:106-107).

Por lo mismo, tal como se concluye en Desde el fogón...: "Lo que no está escriturado en la historia oficial: la oralidad lo apunta y aunque a pata de gallo pase el tiempo bajo el firmamento de Chaurakawin, en su tradición ha quedado este registro" (161), un registro escrito que pone de relieve los componentes culturales, imaginarios e historiográficos de la frontera y de los territorios fronterizos como este entre Rahue y Chauracahuin.

\section{Bibliografía}

Andrade, Paola. Rahue/Imaginario Sur (Poesía y Narrativa). Santiago: Etnika, 2015. Impreso.

Belausteguigoitía, M. "Fronterra", Diccionario de Estudios Literarios Latinoamericanos. Szurmurk, Mónica; Mackee, Robert (Coordinadores). México: Siglo XXI, 2009. 106111. Impreso.

Calderón, Tatiana; Mora, Edith. Afpunmapu, fronteras, borderlands. Poéticas de los confines: Chile-México. Valparaíso: Ediciones Universitarias de Valparaíso, 2015. ."La poética de la frontera en la literatura hispanoamericana contemporánea (ChileMéxico)". Tatiana Calderón, Mora (Ed.). Afunmapu, fronteras, borderlands. Poéticas de los confines: Chile-México. Valparaíso: Ediciones Universitarias de 
Valparaíso, 2015. 21-44. Impreso.

Castoriadis, Cornelius. La institución imaginaria de la sociedad. Buenos Aires: Tusquets, 2007. Impreso.

Castro-Gómez, Santiago. "Ciencias sociales, violencia epistémica y el problema de la "invención del otro". Edgardo Lander (compilador). La colonialidad del saber: eurocentrismo y ciencias sociales. Perspectivas latinoamericanas. La Habana: Editorial de Ciencias Sociales, 2005, 153-172. Impreso.

Castro-Lucic. Los desafíos de la interculturalidad. Identidad. Política, Derecho. Santiago: LOM, 2004. Impreso.

De Sousa Santos, Boaventura. Descolonizar el saber, reinventar el poder, Santiago: LOM, 2013. Impreso.

Dussel, Enrique. Transmodernidad e interculturalidad (Interpretación desde la Filosofía de la Liberación). México: UAM-Iz., 2005. Impreso.

Escobar, Arturo. "Sentipensar con la tierra: las luchas territoriales y la Dimensión ontológica de las Epistemologías del Sur”. AIBR Revista de Antropología Iberoamericana, 11, 1, Enero-Abril (2016): 11-32. Impreso.

Fornet-Betancourt, Raúl. "Supuestos filosóficos del diálogo intercultural”, disponible on line en htttp://then.polylog.org/1/ffr-es.htm

Guerra, Lucía. "La ciudad ajena: subjetividades de origen mapuche en el espacio urbano", en Chile urbano: La ciudad en la literatura y el cine. Magda Sepúlveda (Editora). Santiago: Cuarto Propio, 2013. 187-206. Impreso.

------- "El burdel como sitio de resistencia cultural en Desde el fogón de Graciela Huinao", Estación de la palabra 13, junio (2016). http://www.estaciondelapalabra.cl/

Huinao, Graciela. Desde el fogón de una casa de putas williche. Valdivia: CONADI, 2010. Impreso.

Lander, Edgardo. "Ciencias sociales: saberes coloniales y eurocéntricos". E. Lander (comp.). La colonialidad del saber: eurocentrismo y ciencias sociales. Perspectivas latinoamericanas. La Habana: Editorial de Ciencias Sociales, 2005. 3-40. Impreso.

Maldonado-Torres, Nelson. "La descolonización y el giro descolonial", en Tabula Rasa, 9 (2008): 61-72. Impreso.

Mignolo, Walter. "La colonialidad a lo largo y a lo ancho: el hemisferio occidental en el horizonte colonial de la modernidad". Edgardo Lander (compilador). La colonialidad del saber: eurocentrismo y ciencias sociales. Perspectivas latinoamericanas. La Habana: Editorial de Ciencias Sociales, 2005. 57-85. Impreso.

Mora, Edith. "La encrucijada de los confines". Tatiana Calderón, Mora. (Ed.). Afunmapu, fronteras, borderlands. Poéticas de los confines: Chile-México. Valparaíso: Ediciones Universitarias de Valparaíso, 2015. 11-20. Impreso

Ortiz, Fernando. Contrapunteo cubano del tabaco y el azúcar. (1940). Caracas: Biblioteca Ayacucho, 1978. Impreso.

Quijano, Aníbal. "Colonialidad del poder, eurocentrismo y América Latina”, en Edgardo Lander (compilador). La colonialidad del saber: eurocentrismo y ciencias sociales. Perspectivas latinoamericanas. La Habana: Editorial de Ciencias Sociales, 2005. 216-271. Impreso.

Rama, Ángel. La ciudad letrada. Santiago: Tajamar, 2004. Impreso.

Ramay, Allison. "Una ciudadanía multicultural: representaciones de Graciela Huinao". Magda Sepúlveda. (Ed). Chile urbano: La ciudad en la literatura y el cine. Santiago: Cuarto Propio, 2013. 207-226. Impreso. 
N. Vergara, E. Barraza. Desde el borde de unas aguas fronterizas: para una lectura de Desde el fogón de una casa de putas williche de

Graciela Huinao

Villalobos, Sergio. Vida fronteriza en la Araucanía: el mito de la guerra de Arauco. Santiago: Andrés Bello, 1995. Impreso.

Villalobos, Sergio et alii. Relaciones fronterizas en la Araucanía. Santiago: Universidad Católica, 1982. Impreso.

Walsh, Catherine. "Interculturalidad, plurinacionalidad y decolonialidad: Las insurgencias político epistémicas de refundar el Estado". Tabula Rasa 9 (2008): 131-152. Impreso. 